\title{
A feed-forward spinal cord glycinergic neural circuit gates mechanical allodynia
}

\author{
Yan Lu, ${ }^{1}$ Hailong Dong, ${ }^{1}$ Yandong Gao, ${ }^{1}$ Yuanyuan Gong, ${ }^{1}$ Yingna Ren, ${ }^{1}$ Nan Gu, ${ }^{1}$ \\ Shudi Zhou, ${ }^{1}$ Nan Xia, ${ }^{1}$ Yan-Yan Sun, ${ }^{1}$ Ru-Rong Ji, ${ }^{2}$ and Lize Xiong' ${ }^{1}$
}

\begin{abstract}
1Department of Anesthesiology and Pain Management, Xijing Hospital, Fourth Military Medical University, Xian, People's Republic of China. ${ }^{2}$ Department of Anesthesiology and Neurobiology, Duke University Medical Center, Durham, North Carolina, USA.
\end{abstract}

\begin{abstract}
Neuropathic pain is characterized by mechanical allodynia induced by low-threshold myelinated A $\beta$-fiber activation. The original gate theory of pain proposes that inhibitory interneurons in the lamina II of the spinal dorsal horn (DH) act as "gate control" units for preventing the interaction between innocuous and nociceptive signals. However, our understanding of the neuronal circuits underlying pain signaling and modulation in the spinal DH is incomplete. Using a rat model, we have shown that the convergence of glycinergic inhibitory and excitatory $\mathrm{A} \beta$-fiber inputs onto $\mathrm{PKC} \gamma^{+}$neurons in the superficial $\mathrm{DH}$ forms a feed-forward inhibitory circuit that prevents $A \beta$ input from activating the nociceptive pathway. This feed-forward inhibition was suppressed following peripheral nerve injury or glycine blockage, leading to inappropriate induction of action potential outputs in the nociceptive pathway by $A \beta$-fiber stimulation. Furthermore, spinal blockage of glycinergic synaptic transmission in vivo induced marked mechanical allodynia. Our findings identify a glycinergic feed-forward inhibitory circuit that functions as a gate control to separate the innocuous mechanoreceptive pathway and the nociceptive pathway in the spinal DH. Disruption of this glycinergic inhibitory circuit after peripheral nerve injury has the potential to elicit mechanical allodynia, a cardinal symptom of neuropathic pain.
\end{abstract}

\section{Introduction}

In 1965, Melzack and Wall proposed a well-known hypothesis, the gate theory of pain, which has been highly influential for nearly 50 years (1). However, the theory remains primarily a matter of conjecture, due to insufficient evidence to substantiate the neural circuitry underlying pain signaling and modulation in the spinal dorsal horn (DH). The theory predicts that inhibitory interneurons in the lamina II of the spinal DH act as "gate control" units for the interaction between innocuous and nociceptive signals (1). Mechanical allodynia - pain produced by normally nonpainful mechanical stimuli (e.g., light touch) - is a hallmark of neuropathic pain. It has been proposed that information conveyed via the innocuous mechanoreceptive pathway may gain access to and excite nociceptive pathway in neuropathic pain conditions (2-6). The spinal DH is a relay station in which sensory information is received, integrated, and relayed to several brain regions. Terminals from different functional classes of primary afferents are segregated in different laminae of the spinal DH: thinly myelinated Aס and unmyelinated $\mathrm{C}$ fibers of most nociceptors and some mechanoreceptors innervate the superficial laminae I and II (7-11), whereas touch-sensing, heavily myelinated $A \beta$ fibers of mechanoreceptors terminate in the laminae IIi to IV $(3,10-12)$. Accordingly, under normal physiological conditions, the innocuous and nociceptive pathways are kept separated in the DH. However, pharmacological suppression of DH inhibitory neurons in vivo by antag-

Authorship note: Yan Lu and Hailong Dong contributed equally to this work. Conflict of interest: The authors have declared that no conflict of interest exists.

Note regarding evaluation of this manuscript: Manuscripts authored by scientists associated with Duke University, The University of North Carolina at Chapel Hill, Duke-NUS, and the Sanford-Burnham Medical Research Institute are handled not by members of the editorial board but rather by the science editors, who consult with selected external editors and reviewers.

Citation for this article: J Clin Invest. 2013;123(9):4050-4062. doi:10.1172/JCI70026 onists of glycine or GABAA receptors induces tactile allodynia $(3,4,13)$. In particular, reduced inhibition in the spinal DH after peripheral nerve injury contributes to the genesis of mechanical allodynia (14-16). Therefore, the inhibitory circuit in the spinal $\mathrm{DH}$ is believed to be critical for maintaining the separation of the innocuous and nociceptive pathways $(2-5,16)$.

Studies of pharmacological blockage of GABAergic and/or glycinergic (Gly) synaptic transmission (disinhibition) in the spinal DH and trigeminal system have revealed a novel polysynaptic low-threshold $\mathrm{A} \beta$ fiber input onto lamina I nociceptive neurons $(6,14-19)$. These studies proposed that there is a preexisting connection from the low-threshold mechanoreceptive pathway to the nociceptive pathway, which is normally under strong inhibitory control. Mechanical allodynia in neuropathic pain conditions may thus result from the activation of this preexisting connection, leading to a miscoding of tactile information by cells that normally only respond to painful stimuli $(3,5,20)$.

How the input from mechanoreceptive sensory fibers is processed by the nociceptive pathway in pathological conditions remains unclear, largely because knowledge of the neuronal circuits formed by inhibitory and excitatory interneurons within the spinal DH is at best fragmentary (3). The aims of the present study are (a) to define the circuitry formed by the identified spinal laminae II/III neurons, (b) to examine the responses of the circuitry following A $\beta$-fiber stimulation, and (c) to further investigate the neural plasticity of the circuitry in a neuropathic pain condition. Using simultaneous "paired" patch-clamp recordings, together with anatomical approaches, we identified a specific preexisting excitatory connection from the low-threshold mechanoreceptive pathway to the nociceptive pathway in the spinal DH. This connection is normally silent or ineffective, as it is under strong Gly inhibitory control of a feed-forward inhibitory circuit located in the junction of spinal laminae II/III. This feed-forward inhibition 
A
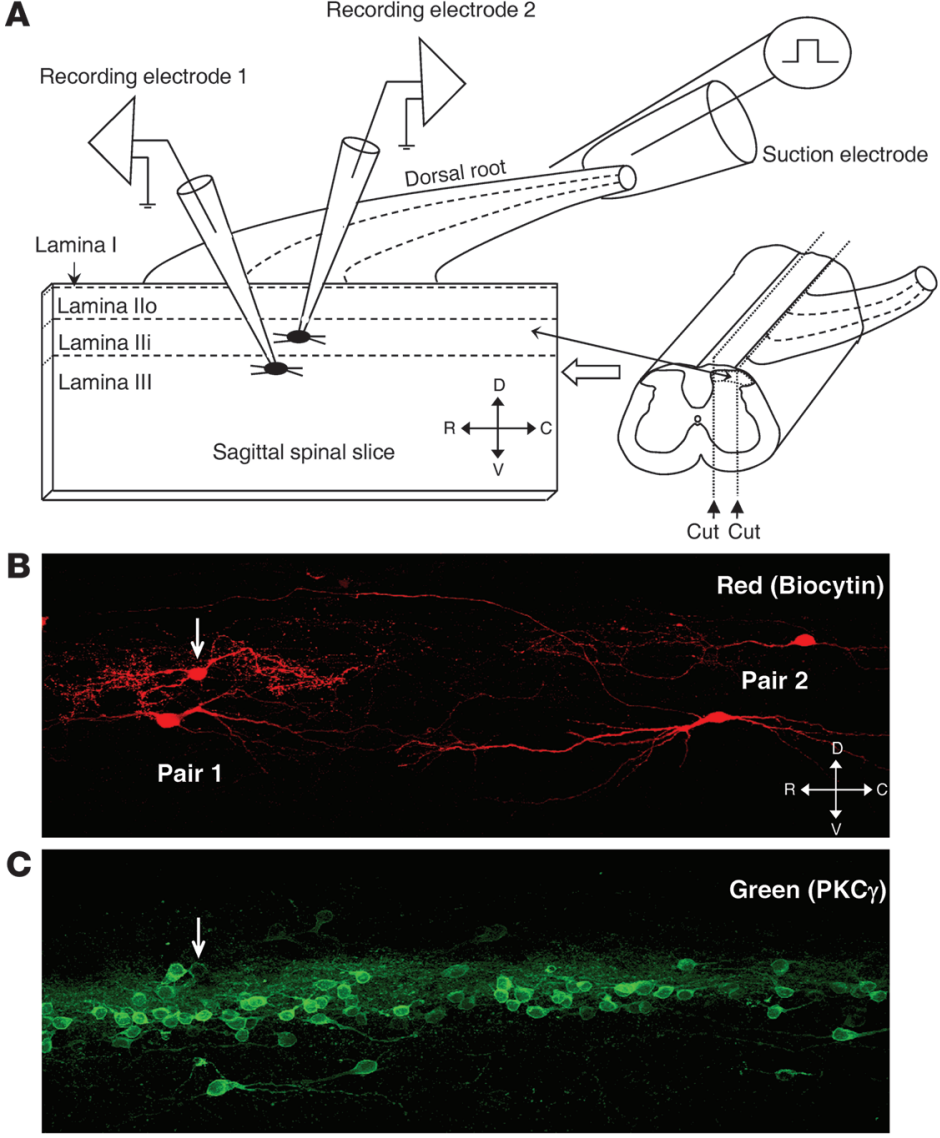

D

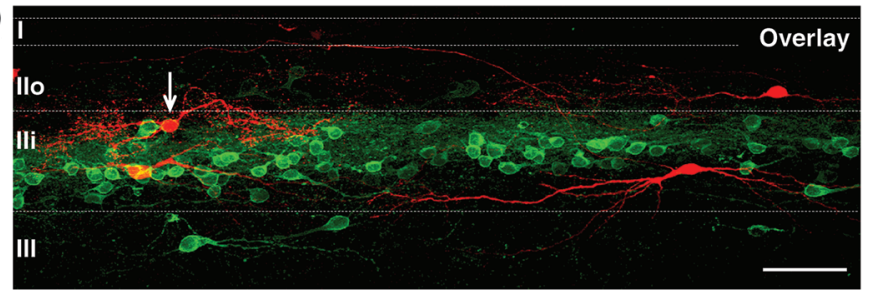

\section{Figure 1}

Illustration of paired patch-clamp recordings in sagittal spinal cord slices. (A) Diagram of the typical experimental paradigm. Sagittal spinal slices (400- to $600-\mu \mathrm{m}$ thick) with an attached DR (8- to 10-mm long) were cut from the lumber spinal cord. Separate recording electrodes were used to make simultaneous whole-cell recordings from 2 neurons located in laminae llo and Ili or laminae Ili and III. A suction electrode was used to stimulate DR to evoke synaptic responses in recorded neurons. C, caudal; $\mathrm{D}$, dorsal; R, rostral; V, ventral. (B) Confocal image of 2 biocytin-labeled pairs of the recorded neurons. (C) Immunostaining shows that $\mathrm{PKC} \gamma$-positive neurons are mainly distributed in lamina Ili. The boundaries of PKC $\gamma$ neuron plexus were used to define lamina IIo, III, and III. (D) The overlay confocal image shows that 1 cell in pair 1 is $\mathrm{PKC} \gamma$ positive (arrow). Scale bar: 100 um. I, lamina I; Ilo, lamina Ilo; Ili, lamina IIi; III, Iamina III.

previously $(3,7,8,24,25)$. Fifty-one out of 242 neuron pairs (21\%) evidenced synaptic connection in the naive rats. Morphological and electrophysiological details were sufficiently complete to allow for identification of 16 pairs as inhibitory connections from lamina III Gly neurons to lamina IIi $\mathrm{PKC} \gamma^{+}$neurons and 18 pairs as excitatory connections from $\mathrm{PKC} \gamma^{+}$neurons to lamina IIo transient central (TC) neurons. The relative locations of the recorded pairs in the slices are shown in Supplemental Figure 1 (supplemental material available online with this article; doi:10.1172/ JCI70026DS1). The remaining 17 pairs (9 inhibitory and 8 excitatory connections) were categorized into unidentified connections, because of insufficient morphological and/or electrophysiological details.

Summary of the unidentified connections in the naive rats. In 3 out of the 9 unidentified inhibitory pairs, the inhibitory postsynaptic potentials (IPSPs) were reversibly eliminated by the GABAA receptor antagonist bicuculline $(10 \mu \mathrm{M})$ but unaffected by the glycine receptor antagonist strychnine $(2 \mu \mathrm{M})$, indicative of a GABA-mediated synaptic transmission. In 2 GABAergic connections, the postsynaptic neuron alone was marked adequately to permit cell-type categorization; both of these were TC neurons. The presynaptic cell was abrogated, as a result of spinal nerve injury or glycine blockage, and, subsequently, activation of the low-threshold $A \beta$ fibers evoked action potentials (APs) in the nociceptive pathway in a neuropathic pain condition produced by spinal nerve ligation (SNL).

\section{Results}

Paired patch-clamp recordings identify synaptic connections of $P K C \gamma^{+}$ neurons in the spinal laminae II/III. PKC $\gamma$-expressing $\left(\mathrm{PKC} \gamma^{+}\right)$interneurons are restricted in lamina IIi and play a key role in the processing of tactile inputs both in physiological and pathological conditions $(12,17,21,22)$. These $\mathrm{PKC} \gamma^{+}$neurons are located right between the laminae in which low-threshold mechanoreceptive and nociceptive inputs terminate, respectively $(3,23)$. We first used simultaneous "paired" patch-clamp recordings, in combination with intracellular biocytin labeling and immunohistochemistry for $\mathrm{PKC} \gamma$, to search for the synaptic connections of $\mathrm{PKC} \gamma^{+}$neurons with neurons located in lamina III or lamina IIo from L5 spinal slices of naive rats. The experimental arrangement is shown in Figure 1. Details of the criteria we used to classify DH neurons and characterize the synaptic connections have been published alone was well labeled in 1 GABAergic pair and was identified as an islet cell type. The other 6 unidentified inhibitory connections were identified as Gly linkages. In 3 of the Gly connections, the postsynaptic neuron alone was marked adequately and was categorized as a $\mathrm{PKC} \gamma^{+}$neuron in 2 pairs and a TC cell in 1 pair. The presynaptic cell alone was well labeled in 1 Gly pair and was identified as an islet cell type. Both neurons of the remaining 2 Gly pairs were not marked well enough to permit cell-type categorization.

In the 8 unidentified excitatory connections, the presynaptic cell alone was well labeled in 1 pair and was identified as a $\mathrm{PKC} \gamma^{+}$ neuron, the postsynaptic neuron alone was marked adequately in 3 pairs and was identified as a TC neuron, and both presynaptic and postsynaptic neurons were unidentified in 4 pairs. More data are needed to determine whether definitive patterns exist, although the examples noted are suggestive of a GABAergic projection and a Gly connection from lamina III to lamina II TC neurons. All of the synaptic connections we found in this study were unidirectional. We did not find any reciprocal connections in the present study, which is focused on the connections between lamina III and lamina II, although we have previously 


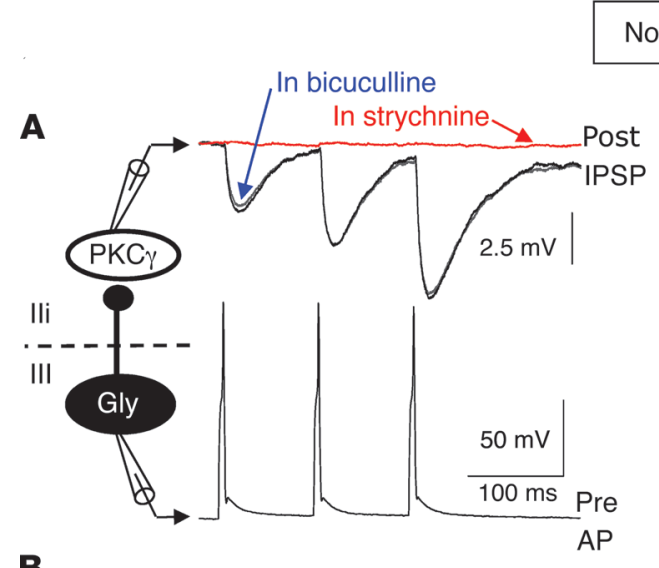

B
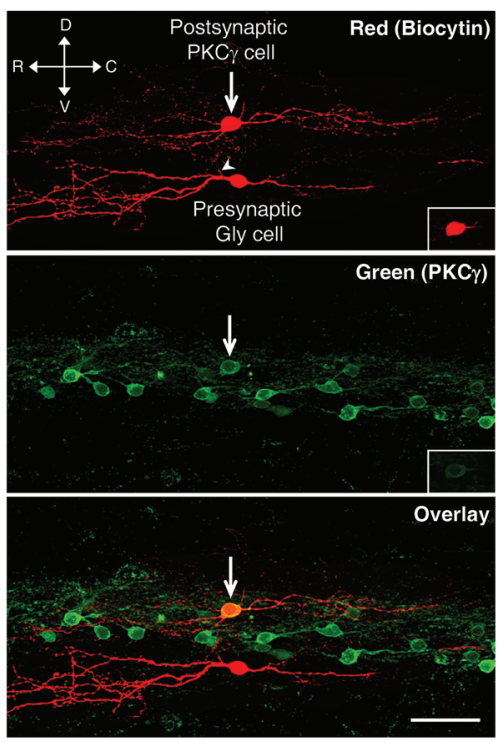

C

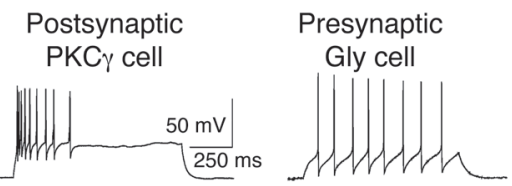

Normal

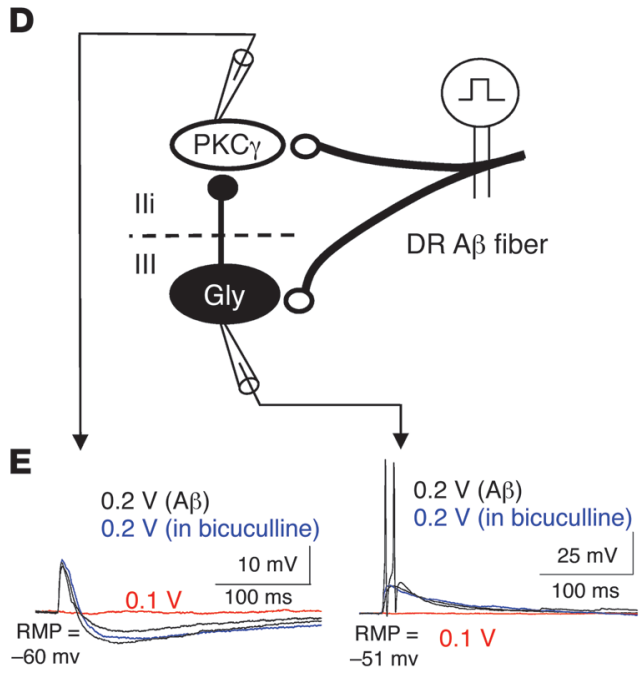

$\mathbf{F}$
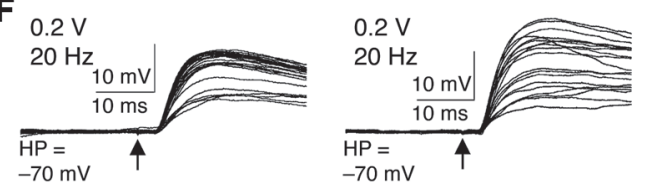

G
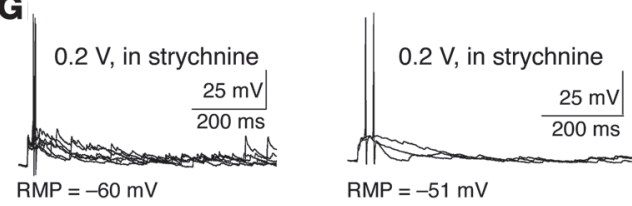

H

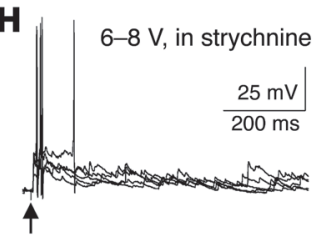

Figure 2). The evoked unitary IPSP had a shorter IPSP rise time $(\approx 10 \mathrm{~ms})$ and duration (50\% decay $\approx 33 \mathrm{~ms}$ ) when compared with GABAergic unitary IPSPs reported previously (rise time $\approx 35 \mathrm{~ms}, 50 \%$ decay $\approx 98 \mathrm{~ms}$ ) (Table 1 and ref. 8). The IPSPs in all pairs were completely blocked by the Gly receptor antagonist strychnine ( $2 \mu \mathrm{M} ; n=16$; Figure 2A) but not affected by the GABAA receptor antagonist bicuculline, even at a high concentration (20 $\mu \mathrm{M} ; n=16$; Figure 2A), indicative of a Glymediated synaptic transmission. The presynaptic cells were located in the lamina III near or in the junction of laminae II/III (Figure 2B and Supplemental Figure 2) and regularly exhibited rather depolarized resting membrane potentials (RMPs; $-50.7 \pm 3.1 \mathrm{mV} ; n=16$ ) and tonic discharge pattern (Figure 2C and Supplemental Table 1). On the other hand, the postsynaptic neurons were all $\mathrm{PKC} \gamma$ positive and located in the lamina IIi (Figure 2B and Supplemental Figure 2), consistently had higher RMPs $(-60.2 \pm 2.7 \mathrm{mV} ; n=16)$ than the presynaptic neurons, and had a high frequency and transient pattern of APs (Figure 2C and Supplemental Table 1). The inhibitory synaptic transmission between Gly neurons and $\mathrm{PKC}^{+}$neurons was generally reliable, as indicated by a relatively low rate of transmission failure $(6 \% \pm 3 \% ; n=16$; Table 1), and exhibited shortterm potentiation following repetitive APs in 100-ms interval (paired-pulse ratio: $1.6 \pm 0.3$; $n=16$; Figure 2A, Supplemental Figure 2, and Table 1).

We next sought to identify the type of primary afferent input to Gly and $\mathrm{PKC} \gamma^{+}$neureported reciprocal connections in the same lamina (lamina II) sampled from mice (26).

A feed-forward inhibitory circuit gates the output of $\mathrm{PKC} \gamma^{+}$neurons following low-threshold A $\beta$-fiber stimulation. We found that 16 pairs of neurons exhibited a common feature: an AP in 1 neuron evoked an IPSP in the other neuron of the pair (Figure 2A and Supplemental rons in the identified inhibitory circuitry using dorsal root (DR) stimulation. Simultaneous recording indicated that DR stimulation evoked synaptic responses in both Gly and $\mathrm{PKC} \gamma^{+}$neurons of the 16 pairs with inhibitory connections (Figure 2, D and E). Based on the stability of the response latency on repeated trials (Figure 2F), the DR-evoked responses were judged to be monos- 
Table 1

Comparison of unitary postsynaptic potentials between naive and SNL rats

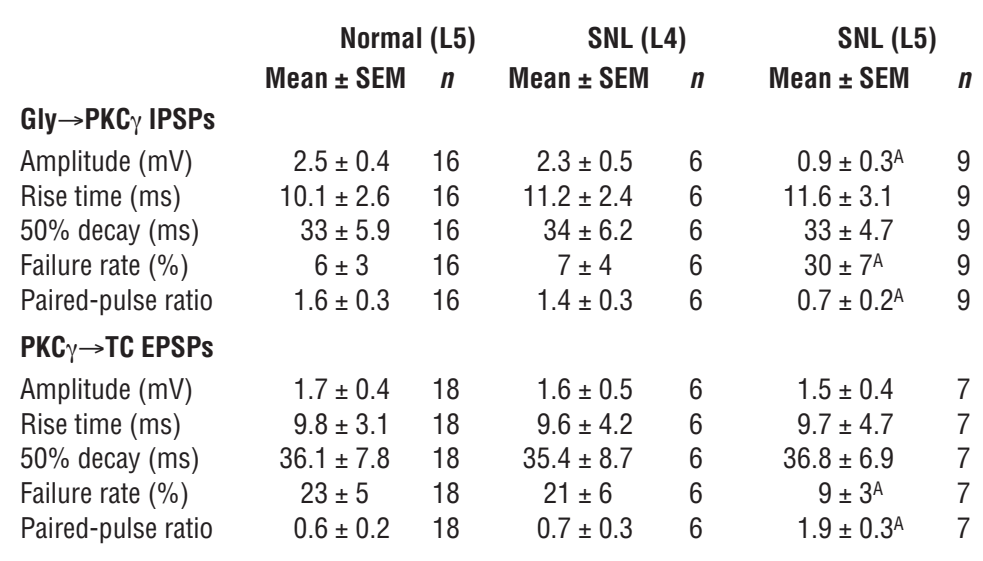

Values are representative of inhibitory synaptic transmission from Gly neurons to $\mathrm{PKC} \gamma^{+}$ neurons, as measured by IPSP amplitude (Gly $\rightarrow$ PKC $\gamma$ IPSPs), and excitatory connections from PKC $\gamma^{+}$neurons to TC neurons, as measured by EPSP amplitude (PKC $\gamma \rightarrow$ TC EPSPs). ${ }^{A}$ Significantly different from controls $(P<0.01) . n$, number of measurements.

from $A \beta$ fibers and inhibitory input (IPSP) from Gly interneurons. Under the control of the inhibitory input, the excitatory input cannot elicit AP output in the $\mathrm{PKC} \gamma^{+}$neurons. But this feed-forward inhibition is attenuated by blocking the Gly synaptic transmission. As a result of this disinhibition, activation of the low-threshold $A \beta$ fibers evokes AP output in $\mathrm{PKC} \gamma^{+}$neurons.

Feed-forward excitatory connections from $\mathrm{PKC} \gamma^{+}$ neurons to nociceptive TC neurons are normally silent after $A \beta$-fiber stimulation. Next, we examined the postsynaptic targets of $\mathrm{PKC} \gamma^{+}$neurons in the lamina II. In 18 pairs that we identified using paired patch-clamp recordings, induction of AP in 1 cell evoked a prompt unitary EPSP, with constant latency in the other (Figure 3A and Supplemental Figure 3). In all cases, the AMPA glutamate receptor antagonist CNQX $(20 \mu \mathrm{M})$ essentially blocked the evoked postsynaptic response (data not shown), indicating a glutamate-mediated synaptic transmission. The presynaptic neurons were all $\mathrm{PKC}^{+}$and located in lamina IIi (Figure 3B and Supplemental Figure 3). Their physiological and morphological features - including the

ynaptic. The latency of the evoked responses for any given pair was very close (variations $<0.2 \mathrm{~ms}$ ) for the presynaptic and postsynaptic cells (Figure 2F). The calculated conduction velocity (CV) of the DR fibers evoking the first phase of these responses was $4.61 \pm 0.3 \mathrm{~m} / \mathrm{s}$ in the presynaptic cells and $4.60 \pm 0.2 \mathrm{~m} / \mathrm{s}$ in the postsynaptic cells $(P>0.05, n=16)$. This $\mathrm{CV}$ is consistent with that of rodent $\mathrm{A} \beta$ fibers recorded at $22^{\circ} \mathrm{C}$ to $25^{\circ} \mathrm{C}(27,28)$. Furthermore, consistent with the homogeny of the latency and $\mathrm{CV}$, the threshold for the DR-evoked response in both neurons was also very close $(0.2 \pm$ $0.02 \mathrm{~V} ; n=16)$. A biphasic response was evoked in the $\mathrm{PKC} \gamma^{+}$cells, characterized by monosynaptic excitatory postsynaptic potentials (EPSPs) and polysynaptic IPSPs ( $n=16$; Figure 2E). The amplitudes of the monosynaptic EPSPs were relatively small, because the IPSPs appeared at the earlier rising phase of the EPSPs. Notably, the IPSPs were eliminated by strychnine $(n=8$; Figure $2 \mathrm{G}$ ) but not by bicuculline $(n=8$; Figure $2 \mathrm{E})$. In the presence of strychnine, the $\mathrm{A} \beta$-fiber strength DR stimulation generated long-lasting EPSPs and, consequently, repetitive APs in PKC $\gamma^{+}$neurons $(n=16$; Figure $2 \mathrm{G})$; the $\mathrm{C}$-fiber strength stimulation did not recruit C-fiber inputs in both $\mathrm{PKC} \gamma^{+}$and Gly neurons $(n=16$; Figure $2 \mathrm{H}$ ). Notably, the Gly neuron type that we characterized here had islet cell-like morphology and a tonic firing pattern. A recent study reported that most parvalbumin-expressing inhibitory neurons concentrated in laminae IIi and III have islet cell-like morphology and receive inputs from myelinated afferents (29). These parvalbumin cells are a possible source of inhibitory presynaptic input onto myelinated primary afferents and may play an important role in the development of tactile allodynia. Further study is needed to characterize the Gly cells and their relationship with parvalbumin cells.

These results indicate the existence of a feed-forward inhibitory circuit in the junction of spinal laminae II/III, in which the Gly inhibitory interneurons and their target $\mathrm{PKC} \gamma^{+}$neurons are activated by the same excitatory input from low-threshold $A \beta$ fibers (Figure 2D). The $\mathrm{PKC} \gamma^{+}$neurons are normally under strong Gly inhibitory control. Upon activation of the low-threshold A $\beta$ fibers, the $\mathrm{PKC} \gamma^{+}$neurons receive 2 types of input, excitatory input (EPSP)
RMPs, pattern of APs, soma sizes, and dendritic characteristics - closely fit that of the $\mathrm{PKC} \gamma^{+}$neurons in the above-mentioned Gly-PKC $\gamma^{+}$connections. Of note, the postsynaptic neurons were all located in the lamina IIo (Figure 3B and Supplemental Figure 3). These neurons exhibited transient firing in response to sustained depolarizing current (Figure 3C). The physiological and morphological features of the postsynaptic neurons in all 18 pairs closely match those of lamina II TC neurons identified previously $(7,8,24,26,30,31)$. The excitatory synaptic transmission from $\mathrm{PKC} \gamma^{+}$neurons to TC neurons was less reliable, as indicated by a relatively high rate of transmission failure $(23 \% \pm 5 \%$; $n=18$; Table 1), and exhibited short-term depression induced by repetitive APs in 100-ms intervals (paired-pulse ratio: $0.6 \pm 0.2, n=$ 18; Figure 3A, Supplemental Figure 3, and Table 1).

The primary afferent input to $\mathrm{PKC} \gamma^{+}$and TC neurons that forms the excitatory connection was also identified using DR stimulation. Simultaneous recording revealed that DR stimulation at $A \beta$ fiber strength $(0.2 \pm 0.02 \mathrm{~V})$ evoked a biphasic synaptic response in $\mathrm{PKC} \gamma^{+}$neurons, monosynaptic EPSPs and polysynaptic IPSPs $(n=18)$, the same as demonstrated in the Gly-PKC $\gamma^{+}$linkages (Figure $3 \mathrm{E}$ ). The $\mathrm{CV}$ of the DR fibers evoking EPSPs in PKC $\gamma^{+}$cells was $4.60 \pm 0.3 \mathrm{~m} / \mathrm{s}(n=18)$. However, the intensity of $\mathrm{A} \beta$-fiber stimulation $(0.2 \pm 0.02 \mathrm{~V}$ ) (or even a higher one that can activate $\mathrm{A} \delta$ fibers, $1.3 \mathrm{~V}$ ) failed to evoke any synaptic response in TC cells (Figure 3, E and F). Only when the stimulus intensity was increased to the range of high-threshold C-fiber intensity $(6.1 \pm 0.3 \mathrm{~V}$; $n=18$ ) were long-latency monosynaptic EPSPs recruited in the TC cells (Figure $3 \mathrm{G}$ ). The CV of the DR fibers evoking EPSPs in the TC cells was $0.31 \pm 0.02 \mathrm{~m} / \mathrm{s}(n=18)$, in alignment with the range of rodent high-threshold $\mathrm{C}$ fibers at $22^{\circ} \mathrm{C}$ to $25^{\circ} \mathrm{C}$ $(8,27,28)$. However, in the presence of strychnine, but not bicuculline (Figure $3 E$ ), DR stimulation at $A \beta$ strength $(0.2 \mathrm{~V})$ - which normally failed to evoke any synaptic response in TC neurons generated $\mathrm{A} \beta$-fiber-mediated EPSPs and repetitive APs both in TC neurons and $\mathrm{PKC} \gamma^{+}$neurons $(n=18$; Figure $3 \mathrm{H})$. The strychnine application did not recruit additional C-fiber inputs, except 


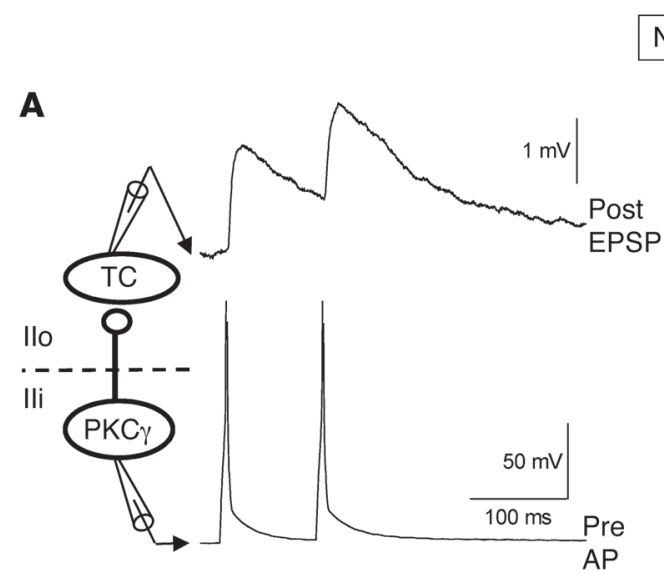

Normal

A

B
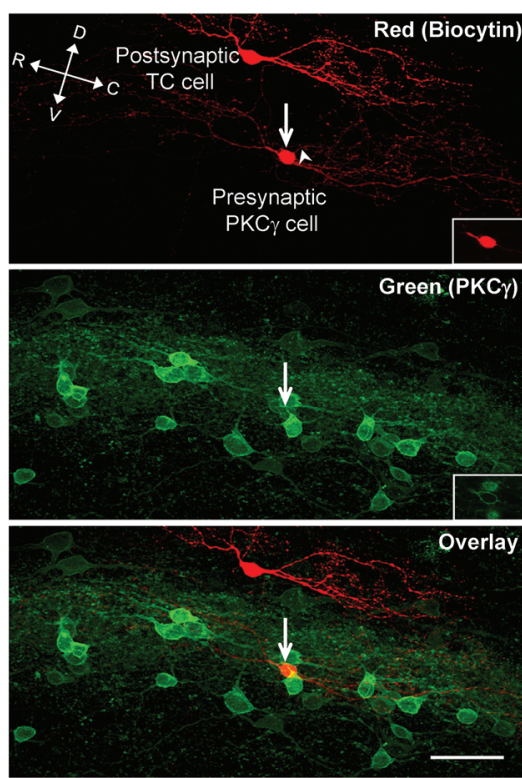

C Postsynaptic<smiles>CCC1C#CCC1C(=O)Cl</smiles>

Presynaptic PKC $\gamma$ cell

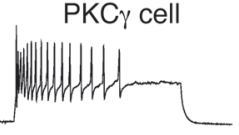

D

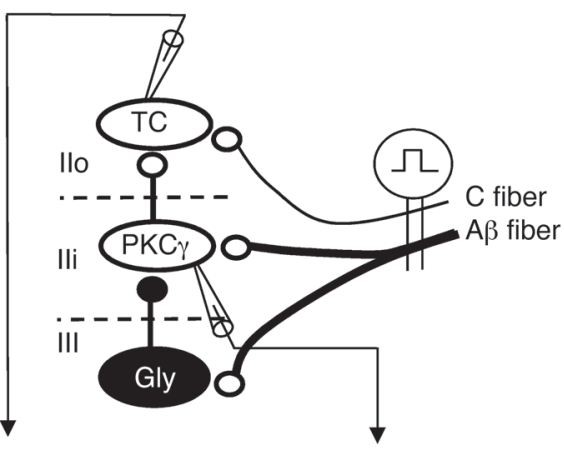

E

$0.2 \vee(A \beta) \quad 0.2 \vee(A \beta)$

$0.2 \mathrm{~V}$ ( in bicuculline) $\quad 0.2 \mathrm{~V}$ ( in bicuculline)
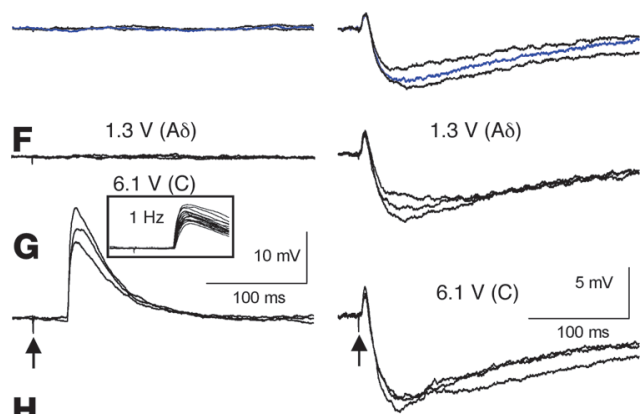

H
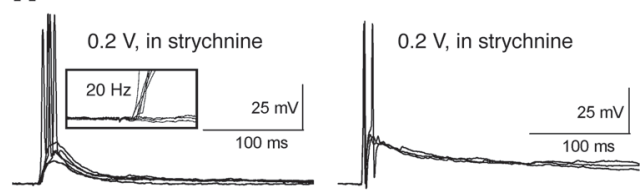

I
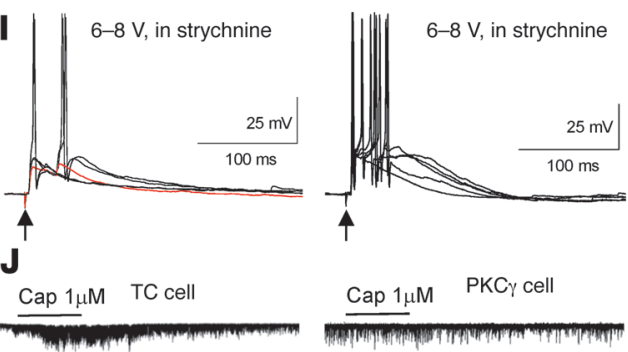

Cap $1 \mu \mathrm{M} \quad$ Gly cell

$\frac{50 \mathrm{pA}}{60 \mathrm{~s}}$

Figure 3

Feed-forward excitatory connections from PKC $\gamma^{+}$neurons to nociceptive TC neurons are normally silent after A $\beta$-fiber stimulation. (A) Unitary excitatory connection between PKC $\gamma^{+}$and TC neurons. post, postsynaptic; pre, presynaptic. (B) Confocal images show 30- $\mu$ m-thick optical stacks of the recorded neuronal pair. Arrows indicate the PKC $\gamma^{+}$cell, and the arrowhead indicates putative axon. Insets indicate 1- $\mu \mathrm{m}$-thick optical stacks of the PKC $\gamma^{+}$cell. Scale bar: $100 \mu \mathrm{m}$. (C) AP patterns of the recorded neurons. (D) Schematic diagram of the excitatory connection and the feedforward inhibitory circuit. (E and F) DR stimulation at $A \beta$ - or A $\mathrm{A}$-fiber strength evokes a biphasic synaptic response in $P K C \gamma^{+}$neurons but fails to evoke a synaptic response in TC cell. (G) DR stimulation at C-fiber strength evokes monosynaptic C-fiber EPSPs in TC cell. The inset shows the consistent latency and lack of synaptic failure during $1-\mathrm{Hz}$ trials. $(\mathbf{H})$ Strychnine blocks the DR-evoked polysynaptic IPSPs and generates long-lasting EPSPs with APs in PKC $\gamma^{+}$neurons and recruits polysynaptic A $\beta$-fiber EPSPs in TC cells. The inset shows the variation of the latency and synaptic failure during $20-\mathrm{Hz}$ trials. (I) Application of strychnine does not recruit additional $\mathrm{C}$-fiber inputs, aside from the original C-fiber inputs in TC neurons. (J) Capsaicin evokes marked increases in mEPSC frequency in TC neurons but has no effect on PKC $\gamma^{+}$and Gly neurons. 
SNL

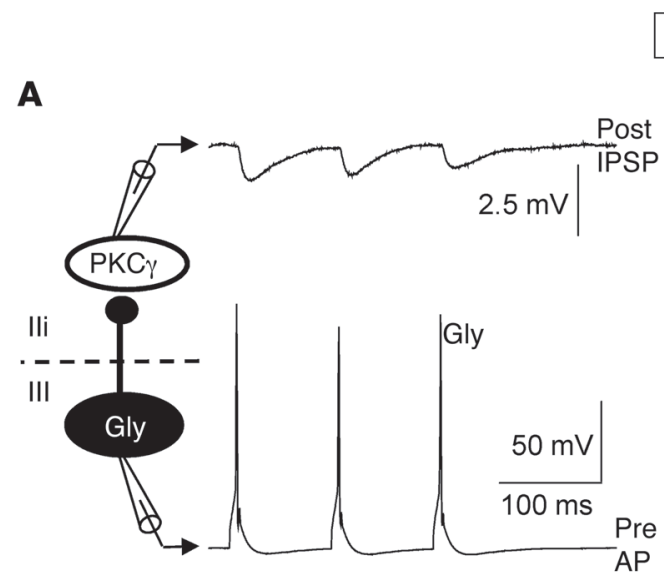

A

\section{B}
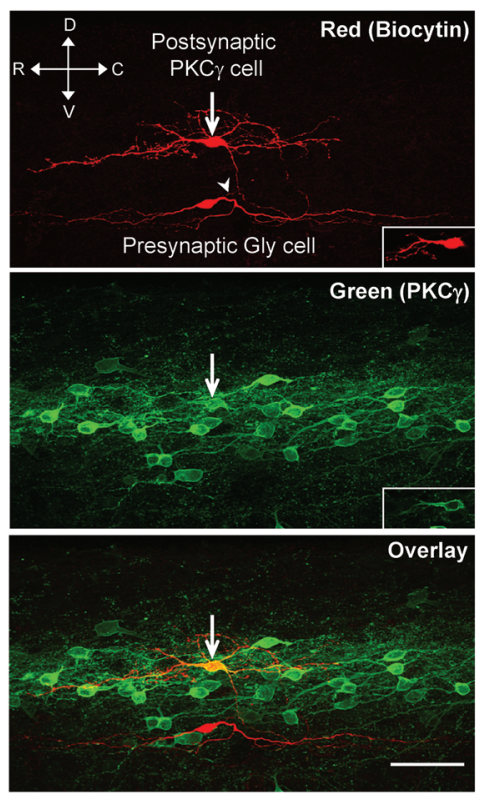

C

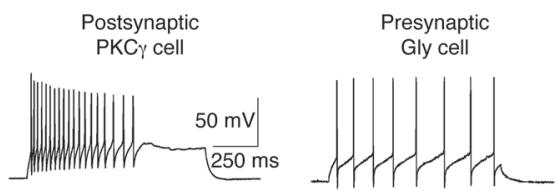

D

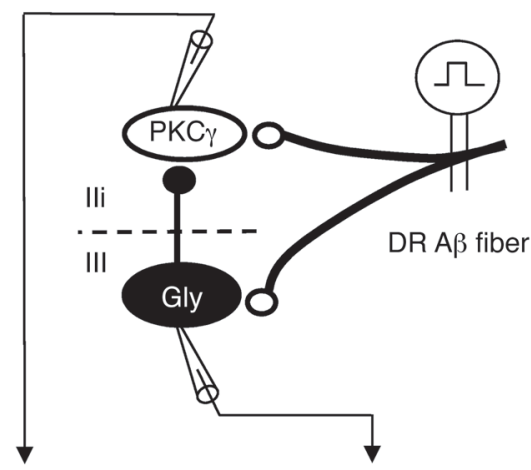

E

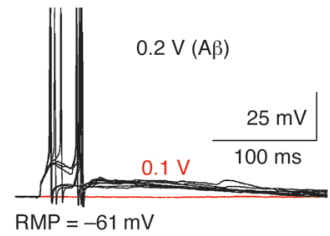

$0.2 \vee(A \beta)$

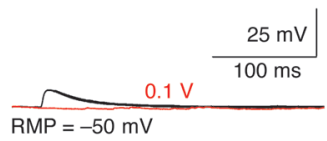

F
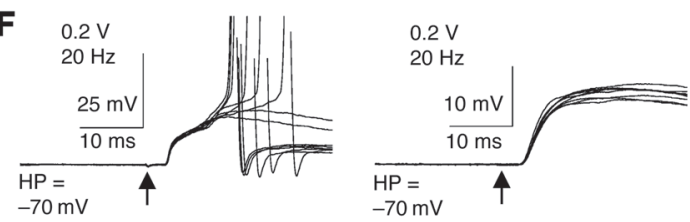

G

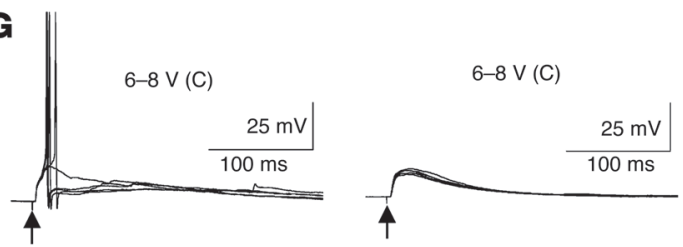

Figure 4

The feed-forward inhibition is impaired after spinal nerve injury. (A) Gly unitary inhibitory connection between Gly and PKC $\gamma^{+}$neurons recorded from a SNL rat. (B) Confocal images show 30- $\mu$ m-thick optical stacks of the recorded neuronal pair. Arrows indicate the PKC $\gamma^{+}$cell, and an arrowhead indicates putative axon. Insets show 1-um-thick optical stacks of the PKC $\gamma^{+}$cell. Scale bar: $100 \mu \mathrm{m}$. (C) AP patterns of the recorded neurons. (D) Schematic diagram of the feed-forward inhibitory circuit. (E) DR stimulation evokes A $\beta$-fiber EPSPs in both Gly and PKC $\gamma^{+}$neurons. The amplitudes of the evoked EPSPs in Gly neurons were significantly smaller than those recorded in naive rats. The polysynaptic inhibitory components revealed in the naive slices almost completely disappeared after SNL. (F) Repetitive DR stimulation $(20 \mathrm{~Hz})$ indicates the evoked EPSPs are monosynaptic. Arrows indicate the stimulus artifacts. (G) DR stimulation at C-fiber strength fails to recruit additional Ad- or C-fiber inputs to PKC $\gamma$ and Gly neurons.

for the original C-fiber inputs in TC neurons $(n=18$; Figure 3I). These EPSPs were polysynaptic in TC neurons and monosynaptic in $\mathrm{PKC} \gamma^{+}$neurons, as evidenced by repeated trials with $20-\mathrm{Hz}$ stimuli $(n=18$; Figure $3 \mathrm{H})$.

Previous studies have defined an explicit circuit in the laminae I and IIo, in which particular combinations of neurons form modules to modify and transmit sensory information from nociceptive primary C fibers $(7,8,32,33)$. The TC neuron is the centerpiece of this nociceptive pathway and receives high-threshold C-fiber input from TRPV1 (26) and Mrgprd (34) nociceptors. Consistent with these prior findings, the TRPV1 agonist capsaicin $(1 \mu \mathrm{M})$ evoked sharp increases in miniature excitatory postsynaptic current (mEPSC) frequency in TC neurons $(287 \% \pm 46 \% ; n=8$; Figure $3 \mathrm{~J})$ but had no effects on mEPSC frequency of $\mathrm{PKC} \gamma^{+}$neurons $(98 \% \pm 5 \%$; 


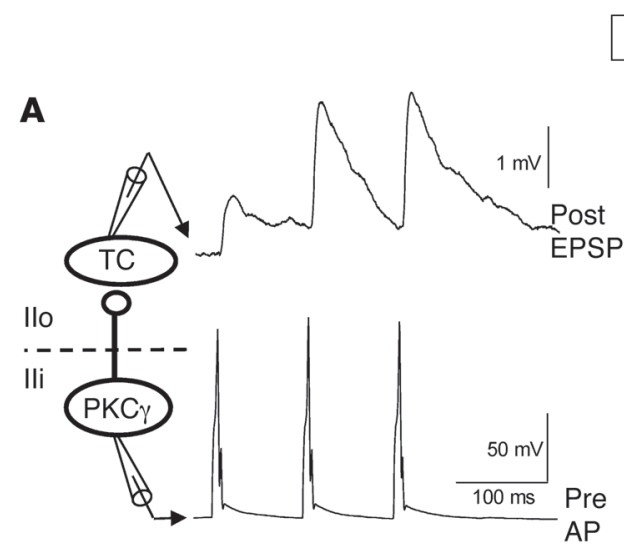

B
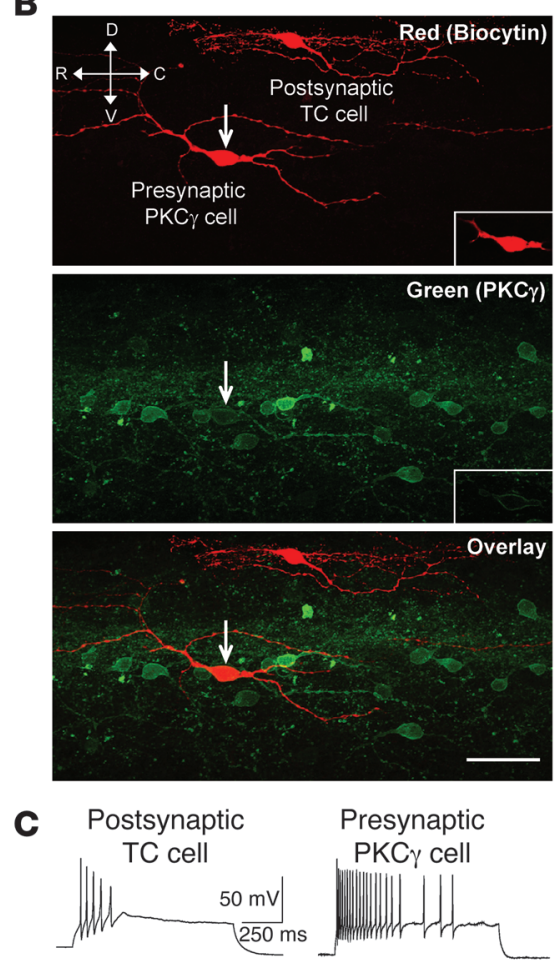

Figure 5

The excitatory connections from $\mathrm{PKC} \gamma^{+}$neurons to TC neurons are enhanced after nerve injury. (A) Unitary excitatory connection between PKC $\gamma^{+}$and TC neurons recorded from a SNL rat. (B) Confocal images show 30- $\mu \mathrm{m}$-thick optical stacks of the recorded neuronal pair. Arrows indicate the PKC $\gamma^{+}$cell. Insets show $1-\mu \mathrm{m}$-thick optical stacks of the PKC $\gamma^{+}$cell. The axon of the PKC $\gamma^{+}$cell was not well labeled. Scale bar: $100 \mu \mathrm{m}$. (C) AP patterns of the recorded neurons. (D) Schematic diagram of the excitatory connection and the feed-forward inhibitory circuit. (E) DR stimulation evokes A $\beta$-fiber EPSPs in both PKC $\gamma^{+}$and TC neurons after SNL. (F) Repetitive DR stimulation $(20 \mathrm{~Hz})$ indicates the evoked EPSPs are monosynaptic in PKC $\gamma$ neurons and polysynaptic in TC cell. (G) DR stimulation at C-fiber strength fails to recruit additional Ad- or C-fiber inputs to TC neurons, aside from the original C-fiber inputs. (H) Capsaicin increases mEPSC frequency in $\mathrm{TC}$ neurons but not in $\mathrm{PKC} \gamma^{+}$neurons.

$n=8$; Figure 3J) and Gly neurons (101\% $\pm 3 \% ; n=7$; Figure 3J).

These data show that $\mathrm{PKC} \gamma^{+}$neurons, which normally receive $\mathrm{A} \beta$ fiber input, make direct excitatory synaptic connections to TC neurons that are part of a C-fiber-mediated nociceptive pathway. This synaptic connection, however, is inefficient in normal physiological conditions, such that A $\beta$-fiber activation fails to evoke AP output in $\mathrm{PKC} \gamma^{+}$neurons, because of a strong feed-forward inhibitory con- trol from Gly neurons. Removal of the Gly inhibition (disinhibition) can convert this ineffective pathway into an efficient one, yielding evoked APs in nociceptive TC neurons following $\mathrm{A} \beta$ fiber activation. The proposed circuit is summarized in Figure 3D.

Identification of synaptic connections of $P K C \gamma^{+}$neurons after spinal nerve injury. To further investigate the functional role of this gate control system in neuropathic pain conditions, we used the same searching strategy to identify the synaptic connections of the $\mathrm{PKC} \gamma^{+}$neurons in L5 or L4 spinal slices from rats with neuropathic pain following ipsilateral L5 SNL. We prepared L4 and L5 spinal cord slices separately 2 weeks after SNL, when mechanical allodynia is fully developed in this model. Forty-four out of 221 neuronal pairs (19.9\%) evidenced synaptic connection in the slices from the SNL rats. Nine and six neuron pairs were identified as having inhibitory connections (from Gly neurons to $\mathrm{PKC}^{+}$neurons) in the L5 and L4 spinal segments, respectively. Seven and six pairs were identified as having excitatory connections (from $\mathrm{PKC} \gamma^{+}$ neuron to TC neuron) in the L5 and L4 spinal segments, respectively. The remaining 16 pairs (9 inhibitory and 7 excitatory connections) were not included in this report, because of insufficient morphological and/or electrophysiological details. The electrophysiological features (RMPs, AP patterns, and AP frequency) of Gly, $\mathrm{PKC}^{+}$, and TC neurons sampled from both L4 and L5 spinal segments of SNL rats did not differ from those sampled from naive rats $(P>0.05$; Supplemental Table 1), suggesting that nerve injury has little effect on the intrinsic excitability of Gly, $\mathrm{PKC}^{+}$, and TC neurons, which is consistent with previous studies $(35,36)$. Thus, it is unlikely that mechanical allodynia in animals with SNL is a result of changes in membrane excitability or discharge pattern of these neurons.

The feed-forward inhibition is impaired after spinal nerve injury. The inhibitory synaptic transmission from Gly neurons to $\mathrm{PKC} \gamma^{+}$neurons in L5 segments became less effective after SNL, as indicated by a decrease in IPSP amplitude $(0.9 \pm 0.3 \mathrm{mV} ; n=9 ; P<0.01$, com- 


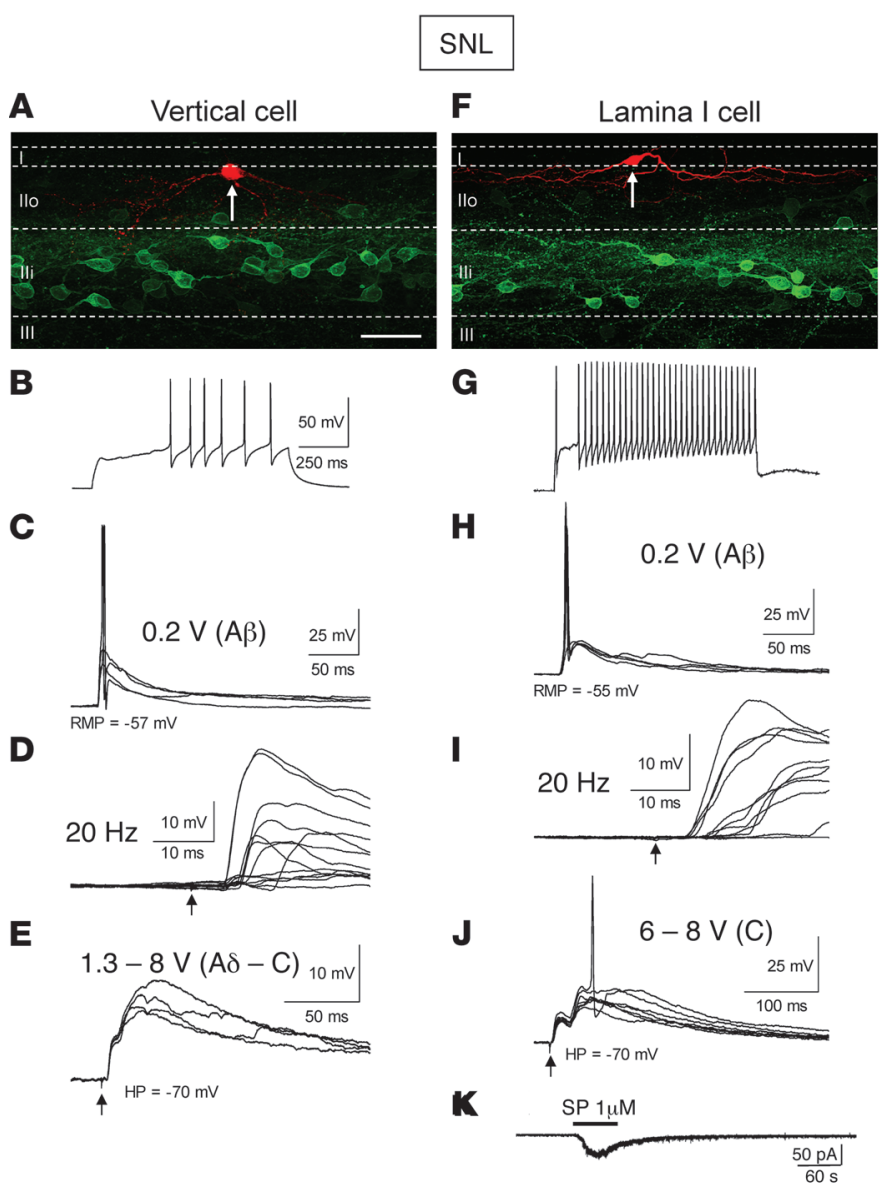

pared with control; Figure 4A, Supplemental Figure 4, and Table 1) and an increase in transmission failure $(30 \% \pm 7 \% ; n=9 ; P<0.001$, compared with control; Table 1). The inhibitory connections also underwent dynamic alteration from short-term potentiation to short-term depression after spinal nerve injury, as demonstrated by the paired-pulse ratio $(0.7 \pm 0.2 ; n=9 ; P<0.01$, compared with control; Figure 4A, Supplemental Figure 4, and Table 1). However, the IPSP amplitude $(2.3 \pm 0.5 \mathrm{mV} ; n=6 ; P>0.05)$, transmission failure rate $(7 \% \pm 4 \% ; n=6 ; P>0.05)$, and paired-pulse ratio $(1.4 \pm 0.3 ; n=6 ; P>0.05)$ sampled from L4 segments were not different from those of the controls following the L4 DR stimulation (Table 1), indicating that plastic changes only occur in the injured segment (L5) but not in the adjacent intact segment (L4). It remains to be investigated whether stimulation of the L5 DR will modulate synaptic transmission in the L4 segment in control and nerve-injured animals.

The excitatory connections from $P K C \gamma^{+}$neurons to TC neurons are enhanced after nerve injury. The excitatory connections from $\mathrm{PKC}^{+}$ neurons to TC neurons in the L5 segments became more effective after spinal nerve injury, as indicated by lower transmission failure ( $9 \% \pm 3 \% ; n=7 ; P<0.01$, compared with control; Figure 5A, Supplemental Figure 5, and Table 1), and exhibited dynamic alteration from short-term depression to short-term potentiation after spinal nerve injury, as demonstrated by the paired-pulse ratio $(1.9 \pm 0.3 ; n=7$; $P<0.01$, compared with control; Figure 5A, Supplemental Figure 5, and Table 1). However, the EPSP amplitude $(1.6 \pm 0.5 \mathrm{mV} ; n=6 ; P>0.05)$, transmission failure rate $(21 \% \pm 6 \% ; n=6 ; P>0.05)$, and paired-pulse

\section{Figure 6}

Activation of low-threshold A $\beta$ fibers evokes AP output of the nociceptive pathway after spinal nerve injury. (A and $\mathbf{F})$ Confocal images of morphology and location of the recorded $(\mathbf{A})$ vertical cell and (F) lamina I cell. Arrows point out the recorded cells. Scale bar: $100 \mu \mathrm{m}$. (B and $\mathbf{G})$ AP firing patterns of vertical and lamina I neurons. ( $\mathbf{C}$ and $\mathbf{H}$ ) DR stimulation at $A \beta$ strength recruits polysynaptic EPSPs with APs in (C) vertical and (H) lamina I neurons. ( $\mathbf{D}$ and I) The EPSPs are polysynaptic, as demonstrated by the varied latency and synaptic failure during 20-Hz stimulation. ( $E$ and $\mathbf{J}$ ) DR stimulation at C-fiber strength fails to recruit additional $A \delta$ - or $\mathrm{C}$-fiber inputs to vertical and lamina I neurons, aside from their original $A \delta$ - and C-fiber inputs. (K) Substance P (SP) $(1 \mu \mathrm{M})$ evokes inward current in lamina I neurons. ratio $(0.7 \pm 0.3 ; n=6 ; P>0.05)$ sampled from $L 4$ segments did not differ when compared with those of the controls (Table 1 ).

Activation of low-threshold A $\beta$ fibers evokes AP output of nociceptive pathway after spinal nerve injury. We next examined the plasticity of the primary inputs to the gate control circuit after SNL. DR stimulation at $A \beta$ strength $(0.2 \pm 0.02 \mathrm{~V})$ evoked monosynaptic EPSPs in Gly neurons (RMPs, $-50.2 \pm 2.7 \mathrm{mV} ; n=9$ ) recorded from the L5 slices of the SNL rats $(n=9$; Figure 4, E and F). The amplitudes of the DR-evoked EPSPs in Gly neurons $(9.5 \pm 2.1 \mathrm{mV} ; n=9$; Figure 4E) were significantly smaller $(P<0.01)$ than those recorded in naive rats $(19.3 \pm 3.2 \mathrm{mV} ; n=16$; Figure $2 \mathrm{E})$. DR stimulation at the same strength evoked monosynaptic EPSPs superimposed with APs in all $\mathrm{PKC} \gamma^{+}$neurons, and the polysynaptic inhibitory components revealed in the naive slices (Figure 2E) almost completely disappeared after SNL ( $n=16$; Figure 4E and Figure $5 \mathrm{E})$. $\mathrm{DR}$ stimulation at $\mathrm{A} \beta$ strength $(0.2 \pm 0.02 \mathrm{~V})$ recruited polysynaptic EPSPs in all 7 nociceptive TC neurons (Figure 5, E and F), 5 out of 7 vertical neurons (Figure 6, A-E), and 6 out of 9 lamina I substance $\mathrm{P}-$ sensitive neurons (Figure 6, F-K). The vertical and lamina I substance $\mathrm{P}$-sensitive neurons normally only receive nociceptive A $\delta$ - and C-fiber input, respectively $(7,8)$. Recording at RMPs, all of these A $\beta$-fiber-mediated polysynaptic EPSPs were superimposed with APs (Figure 6, C and $\mathrm{H}$ ), indicating that AP outputs were evoked by A $\beta$-fiber activation. As the TC, vertical, and NK-1expressing lamina I neurons (substance P-sensitive; Figure 6K) are part of a nociceptive pathway identified in the superficial $\mathrm{DH}(7,8,26,33,34,37)$, these results indicate that activation of 
A
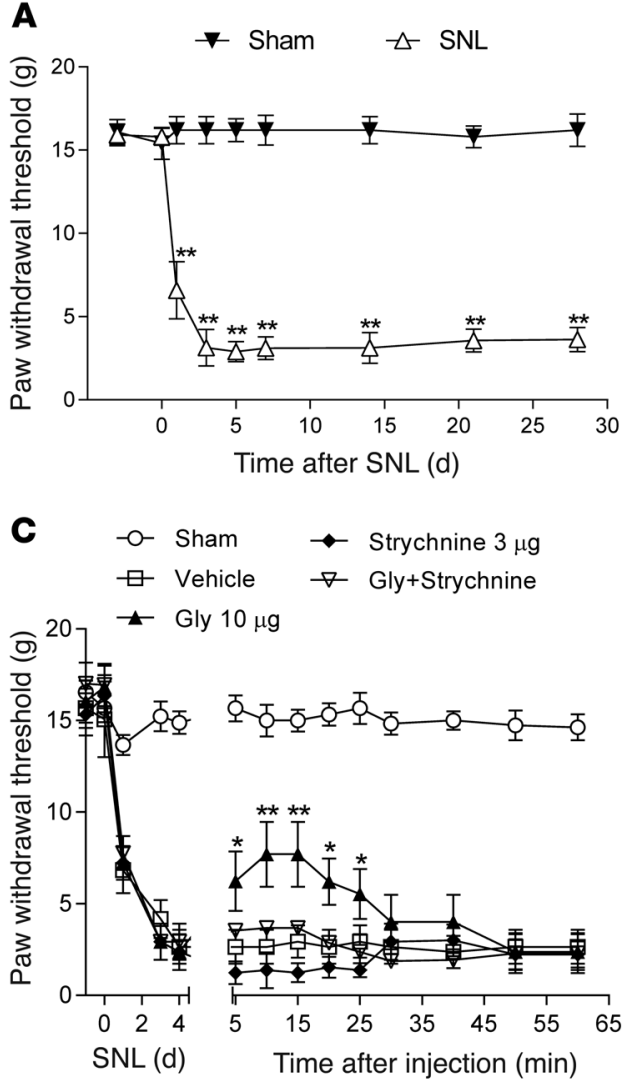

E

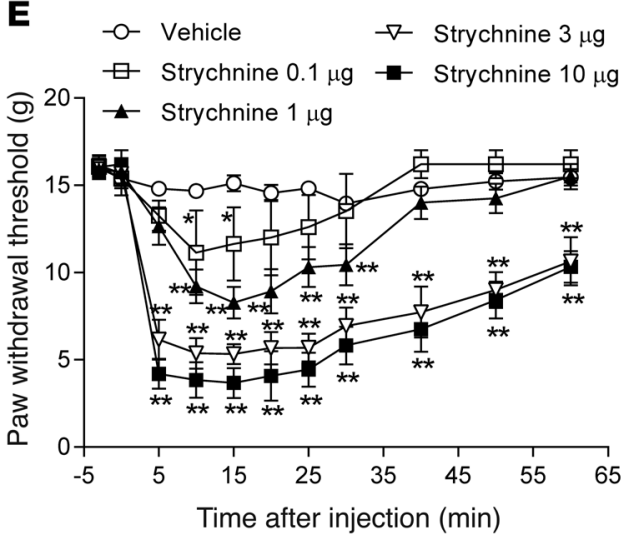

B
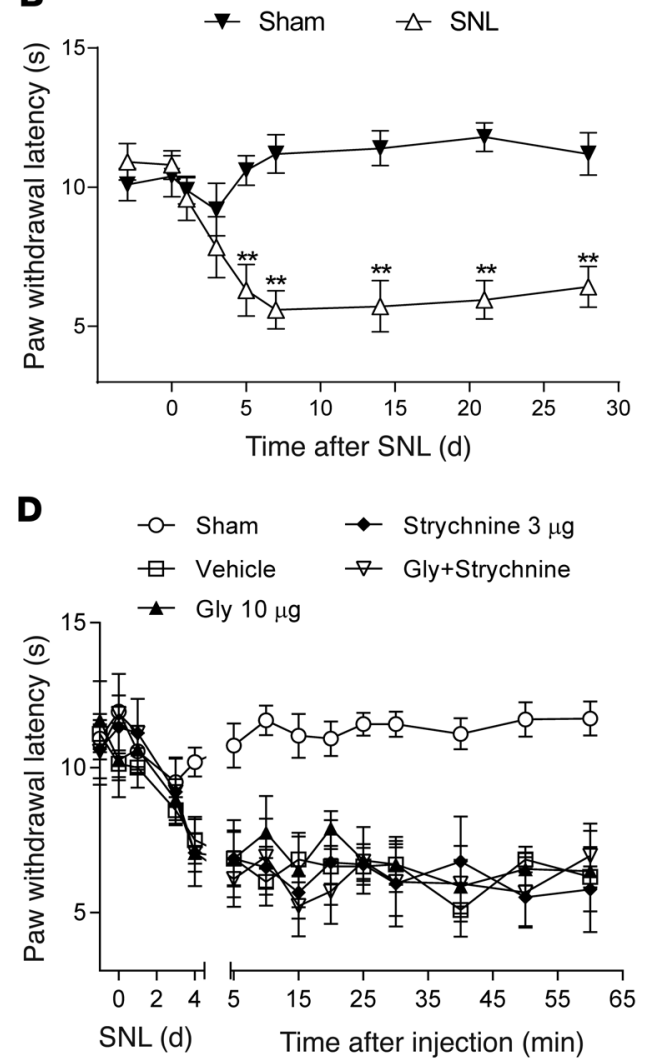

$\mathbf{F}$

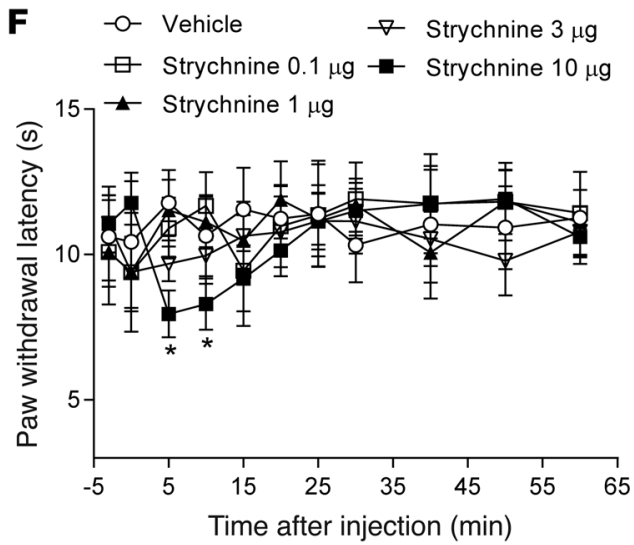

\section{Figure 7}

Blockage or activation of spinal Gly synaptic transmission differentially regulates mechanical allodynia. (A and B) SNL induced (A and $\mathbf{C})$ mechanical allodynia and (B and $\mathbf{D}$ ) thermal hyperalgesia manifested as a lowered threshold of mechanical or thermal withdrawal in rats. Ten rats were included in each group. (C and D) The SNL-induced mechanical allodynia was attenuated by intrathecal glycine, and this effect was blocked by strychnine. The same dose of glycine had no effect on the SNL-induced thermal hyperalgesia. Six rats were included in each group. (E and $\mathbf{F}$ ) Intrathecal injection of strychnine induced robust mechanical allodynia but mild thermal hyperalgesia in naive rats. Six rats were included in each group. ( ${ }^{*} P<0.05$, ${ }^{\star \star} P<0.01$, compared with vehicle or sham controls, 1-way ANOVA with Bonferroni post-hoc test). low-threshold A $\beta$ fibers is able to evoke AP output in the spinal nociceptive pathway after SNL. DR stimulation at C-fiber strength (6-8 V) failed to recruit additional Ad- or C-fiber inputs to $\mathrm{PKC} \gamma$ ( $n=16$; Figure 4G and Figure 5G), Gly ( $n=9$; Figure 4G), TC $(n=7$; Figure $5 \mathrm{G})$, vertical $(n=7$; Figure $6 \mathrm{E})$, and lamina I neurons $(n=9$; Figure $6 \mathrm{~J}$ ), except the original $\mathrm{A} \delta$ - and $\mathrm{C}$-fiber inputs to vertical and lamina I neurons (Figure 6, E and J). These results indicate that nerve injury or glycine blockade can only recruit $A \beta$ fibers, but not Ad or C fibers, to the nociceptive pathway.

Activation or blockade of spinal Gly synaptic transmission differentially modulates mechanical allodynia. SNL induced rapid $(<1 \mathrm{~d})$ and persistent (>28 d) mechanical allodynia, a reduction in paw withdrawal threshold (Figure 7A), and heat hyperalgesia, a reduction in paw withdrawal latency (Figure 7B), in rats. The SNL-induced mechanical allodynia was attenuated by intrathecal injection of glycine $(10 \mu \mathrm{g}$ in $10 \mu \mathrm{l})$, and this effect could be blocked by strychnine ( $3 \mu \mathrm{g}$; Figure $7 \mathrm{C})$, in alignment with previous studies (38-40). But the same dose of glycine had no effects on the heat hyperalgesia (Figure 7D). To determine whether strychnine is sufficient to induce pain hypersensitivity in naive animals, we tested dose-dependent effects of strychnine $(0.1,1.0,3.0$, and $10.0 \mu \mathrm{g})$. Higher doses of strychnine $(>10.0 \mu \mathrm{g})$ may cause seizure. Consistent with previous studies $(13,17,41,42)$, intrathecal strychnine induced marked mechanical allodynia in a dose-dependent manner (Figure 7E). However, only the highest subconvulsive dose of strychnine $(10 \mu \mathrm{g})$ induced thermal hyperalgesia (Figure $7 \mathrm{~F})$. These in vivo results strongly support our conclusion that disinhibition of spinal Gly inhibitory circuit after peripheral nerve injury may open the gate to elicit mechanical allodynia. 


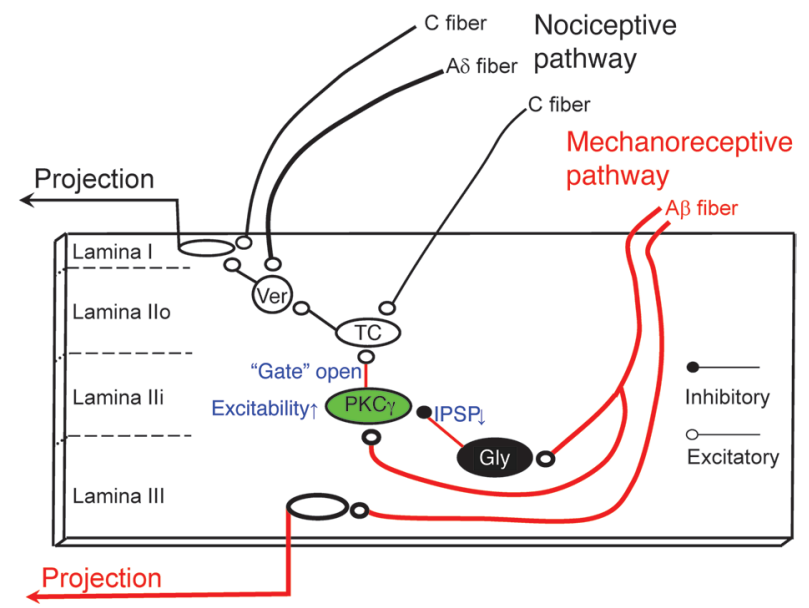

Figure 8

Working hypothesis of the "gate control" circuit for the generation of mechanical allodynia after nerve injury. There is a preexisting but normally silent excitatory linkage from $\mathrm{PKC} \gamma^{+}$cell to TC cell. This connection is normally under strong Gly control of a feed-forward inhibitory circuit. Nerve injury results in disinhibition of $\mathrm{PKC} \gamma^{+}$neurons and allows the low-threshold mechanoreceptive signals to activate the nociceptive pathway.

\section{Discussion}

Our findings identified a preexisting, but normally silent, excitatory linkage from the low-threshold mechanoreceptive pathway to the nociceptive pathway in the spinal DH. This connection is normally under strong Gly inhibitory control via a feed-forward inhibitory circuit located at the junction of spinal laminae II/III, but, strikingly, this feed-forward inhibition is abrogated after peripheral nerve injury or glycine blockage, and, as a consequence, polysynaptic A $\beta$-fiber inputs are recruited to evoke AP outputs in the nociceptive pathway. We also demonstrated that blockage of spinal Gly synaptic transmission induces marked mechanical allodynia. These results suggest that nerve injury-induced disinhibition of the Gly inhibitory circuit may lead to the development of mechanical allodynia in neuropathic pain conditions. The present study thus provides strong evidence that this Gly feed-forward inhibitory circuit is the prime determinant maintaining separation between the innocuous mechanoreceptive pathway and the nociceptive pathway, serving as a gate control (Figure 8). Mechanical allodynia in neuropathic pain conditions may thus result from the activation of the preexisting connection between the innocuous mechanoreceptive pathway and the nociceptive pathway, leading to a miscoding, with cells that normally respond to noxious stimuli being activated by tactile input. In addition, other circuits such as GABAergic circuit may also contribute to the gate control, as we have found some GABAergic inhibitory connections in this region. Sprouting of $A \beta$ afferents dorsally into laminae IIo and I, the area that normally receives nociceptive input, was also implicated in nerve injury-induced mechanical allodynia (43-47), but several latter studies argue against the hypothesis of $A \beta$ afferent sprouting $(12,48,49)$.

Previous studies using single patch-clamp recordings or anatomical approaches have proposed that pharmacological inhibition of GABAergic and GABAergic/Gly systems may activate a preexisting pathway (polysynaptic) from deep to superficial laminae in the spinal DH or trigeminal system, leading to abnormal pain sensations, such as allodynia $(5,6,14,17-19,50)$. Microglia-released mediators, such as BDNF, have also been shown to increase the excitability of lamina I neurons, due to attenuation of GABAergic and/or Gly inhibition induced by downregulation of the chloride transporter KCC2 $(51,52)$. Glia-produced proinflammatory cytokines, such as IL-1 $\beta$ and IL-6, were also shown to suppress GABAergic and Gly transmission in the DH (53). However, the nature of the conventional whole-cell recordings in the present study prevented us from seeing functional consequences of impaired chloride homeostasis.

Our previous studies have reported that substantial inhibitory synapses in the lamina II are mediated by GABA only $(7,8,26)$. The present study suggested that most of the inhibitory synapses from lamina III to lamina II are mediated by glycine only. We did not find any inhibitory synapse in the superficial DH that was mediated by both glycine and GABA. This finding contradicts some earlier reports but is also supported by recent reports. Immunohistochemical studies indicate that within laminae I-III, glycine immunoreactivity is largely restricted to GABA-containing cells $(3,4)$. This suggests that many inhibitory interneurons corelease GABA and glycine, whereas others release only GABA. However, electrophysiological studies have identified synapses in this region that are purely Gly $(3,54,55)$. Although these may involve axons that originate from Gly neurons located outside laminae I-III, in many cases the lack of a GABAergic component probably results from the absence of GABAA receptors at these synapses (3). Glycine receptor $\alpha 3$ subunit (GlyR $\alpha 3$ ) is distinctly expressed in spinal lamina IIi overlapping with $\mathrm{PKC} \gamma$ neurons and is proposed to be selectively involved in pathological pain states (56). These studies thus support our findings that lamina III Gly neurons are critical for gating pathological pain. The spinal long-term depression has been recently reported to regulate GABAergic neuron-mediated disinhibition and the development of neuropathic pain (57). The present study suggests that Gly neuron-mediated disinhibition may also be involved in the development of longterm depression, because the amplitudes of the DR-evoked EPSPs in Gly neurons after spinal nerve injury were significantly smaller than those recorded in naive rats. Further investigation is needed to examine the cause of Gly neuron-mediated disinhibition.

It is worth mentioning that some $\mathrm{A} \delta$ and $\mathrm{C}$ primary afferent neurons projecting to the spinal lamina II convey information about innocuous thermal and mechanical events (9). The central terminals of physiologically characterized hair follicle afferents have also been shown to contact PKC $\gamma$-positive neurons in the rat (12). Our previous electrophysiological study also suggested that spinal lamina II contains a modular circuit that undergoes interaction between low-threshold and high-threshold primary C fibers (8). A recent genetic labeling study (10) further confirmed that spinal lamina II receives some projections from low-threshold Ad- and C-fiber mechanoreceptors. Notably, lamina II TC cells have been revealed, in the present and previous studies $(7,8)$, to receive projection from high-threshold primary $C$ fibers.

The key contribution of the gate control theory is the emphasizing of a central neural mechanism of pain control via interactions between excitatory and inhibitory neurons (58). Although some points of the theory have been found to reflect an oversimplification of the central nervous system or to even be plainly wrong as to the organization of the peripheral input to the spinal cord, the gate theory has had a profound impact on the pain research and has helped to draw attention to previously unrecognized aspects of pain modulations (59). It is now clear that the specificity theory of 
pain emphasizes the role of nociceptors in the mediation of nociceptive pain in normal physiological conditions (60-62), and the gate theory emphasizes the contribution of altered central processing to pain hypersensitivity in pathological conditions (62). Our study found a novel "gate" in the spinal $\mathrm{DH}$, with definite morphological and functional details, in which activation of low-threshold nonnoxious $A \beta$ fibers in the neuropathic pain condition "opens" the gate to mechanical allodynia, a neuropathic pain symptom.

\section{Methods}

Animals and spinal slice preparation. Male Sprague-Dawley rats (6 weeks old) were used for this study. Parasagittal spinal slices were prepared as previously described (refs. 7, 8, and Figure 1). Animals were deeply anesthetized with urethane $(1.5 \mathrm{~g} / \mathrm{kg}$, i.p.) and then perfused transcardially for 2 minutes with ice-cold sucrose-substituted ACSF (sucrose ACSF: $75 \mathrm{mM}$ sucrose; $80 \mathrm{mM} \mathrm{NaCl} ; 2.5 \mathrm{mM} \mathrm{KCl} ; 0.5 \mathrm{mM} \mathrm{CaCl}_{2} ; 1.2 \mathrm{mM} \mathrm{MgCl}_{2} ; 1.25 \mathrm{mM}$ $\mathrm{NaH}_{2} \mathrm{PO}_{4} ; 25 \mathrm{mM} \mathrm{NaHCO} ; 1.3 \mathrm{mM}$ ascorbate; and $3.0 \mathrm{mM}$ pyruvate). The lumbosacral spinal cord with DRs (>10-mm long) attached was quickly removed and placed in ice-cold sucrose ACSF. Parasagittal (400- to 600- $\mu$ m-thick) lumbar spinal cord (L5 or L4) slices with attached DRs were prepared in ice-cold sucrose ACSF using a vibrating microtome. The slices were then maintained and studied at room temperature $\left(22^{\circ} \mathrm{C}-25^{\circ} \mathrm{C}\right)$ in regular ACSF equilibrated with $95 \% \mathrm{O}_{2}$ and $5 \% \mathrm{CO}_{2}$ (ACSF: $125 \mathrm{mM} \mathrm{NaCl} ; 2.5 \mathrm{mM} \mathrm{KCl} ; 2 \mathrm{mM} \mathrm{CaCl}_{2} ; 1 \mathrm{mM} \mathrm{MgCl}_{2} ; 1.25 \mathrm{mM} \mathrm{NaH}_{2} \mathrm{PO}_{4}$; $26 \mathrm{mM} \mathrm{NaHCO}_{3} ; 25 \mathrm{mM}$ D-glucose; $1.3 \mathrm{mM}$ ascorbate; and $3.0 \mathrm{mM}$ pyruvate). To study the plastic changes of $\mathrm{DH}$ circuits in the neuropathic pain condition, the spinal slices were made 2 weeks after SNL when mechanical allodynia was fully developed (Figure 7A).

Electrophysiological recordings. The electrophysiological recording procedures, labeling, and identification of neuronal types were described previously $(7,8)$. Whole-cell recordings were obtained simultaneously from $2 \mathrm{DH}$ neurons using infrared guidance (visualized by a CCD camera). Careful note was made of the locus of each recorded cell relative to landmarks on the slice. At most, 2 pairs of neurons were studied in a slice (Figure 1). In our patchclamp recordings, the firing pattern of each neuron was determined by 1 -s depolarizing pulses from the holding potential of $-60 \mathrm{mV}$. Each neuron of a simultaneously recorded pair was stimulated with 10 -ms rectangular 0.1 - to $20-\mathrm{Hz}$ current pulses to generate APs in the search for synaptically evoked responses in the other cell. The whole-cell recording electrodes contained biocytin ( $0.5 \%$ in an internal solution consisting of the following: $130 \mathrm{mM}$ K-gluconate, $5 \mathrm{mM} \mathrm{KCl}, 4 \mathrm{mM}$ Mg-ATP, $10 \mathrm{mM}$ phosphocreatine, $0.3 \mathrm{mM}$ Li-GTP, and $10 \mathrm{mM}$ HEPES, pH 7.3, $300 \mathrm{mOsm}$ ).

Graded 0.1- to 0.5 -ms pulses delivered through a suction electrode were used to initiate afferent volleys in the DR (8- to 10-mm long from the tip of the suction electrode to the recording site). The CVs of primary afferent fibers evoking monosynaptic EPSPs were estimated from the latency of the evoked response and the conduction distance. The DR-evoked postsynaptic potentials were elicited by graded intensity to recruit $A \beta, A \delta$, and $C$ fibers. Classification of whether synaptic responses were from $A \beta, A \delta$, and $\mathrm{C}$ fibers was based on a combination of response threshold and CV. A- or C-fiber-evoked EPSPs were judged to be monosynaptic if they had a constant latency and absence of failures in 20 - or $1-\mathrm{Hz}$ repetitive trials $(7,8,63$, 64). In a separate experiment, the response thresholds and CVs for $A \beta, A \delta$, and $C$ fibers were determined under our recording conditions (Supplemental Figure 6). The DR was stimulated orthodromically (0.1 ms for A fiber, $0.5 \mathrm{~ms}$ for $\mathrm{C}$ fiber) and compound APs were recorded extracellularly at its central end. The stimulus intensities for activation of $A \beta, A \delta$, and $C$ fibers were determined at 0.1 to $0.5 \mathrm{~V}, 0.6$ to $1.3 \mathrm{~V}$, and 2 to $10 \mathrm{~V}$ in our recording conditions. The methods for electrophysiological data acquisition and analysis of synaptic responses were performed as previously described $(7,8)$.
Surgery. To produce SNL, rats were anesthetized with isoflurane, and the right side $\mathrm{L} 5$ transverse process was removed to expose the L4 and L5 spinal nerves. The L5 spinal nerve was then isolated and tightly ligated with 6-0 silk thread. Sham surgery (exposure of the spinal nerves without ligation) was used as control (65).

Pharmacological agents and administration. Stock solutions of strychnine (Sigma-Aldrich), bicuculline (Sigma-Aldrich), CNQX (Tocris), capsaicin (Sigma-Aldrich), substance P (Sigma-Aldrich), TTX (Sigma-Aldrich), and glycine were diluted in ACSF just before being used for bath application or intrathecal injection. The drug doses were selected on the basis of previous reports and our preliminary experiments. Strychnine and glycine were delivered intrathecally (in a volume of $10 \mu \mathrm{l}$ ) into cerebral spinal fluid through lumbar puncture made by a 27-gauge needle between L5 and L6, under a brief anesthesia with isoflurane. A successful spinal puncture was evidenced by a brisk tail-flick when the needle entered into the subarachnoid space. Other agents were bath applied during electrophysiological recordings.

Behavioral analysis. All behavioral tests were performed by a blinded observer. The preoperative testing began 3 days prior to surgery and was used to establish baseline behavior. To measure mechanical threshold, rats were placed in plastic chambers on a mesh floor. After acclimatization (30 minutes), mechanical nociceptive thresholds were determined by paw withdrawal to stimulation of the glabrous surface of the paw. Calibrated von Frey filaments (Stoelting; 1, 1.5, 2, 4, 6, 8.3, 11.1, 16.5, and $26 \mathrm{~g}$ ) were applied with enough force to cause buckling of the filament. The $50 \%$ paw withdrawal threshold to elicit a robust withdrawal response was determined using Dixon's up-down method. To measure the thermal latency, rats were placed in plastic chambers on the surface of a 2-mm-thick glass plate and allowed 30 minutes for habituation before examination. Heat sensitivity was tested by radiant heat using Hargreaves apparatus (IITC Life Science) and expressed as paw withdrawal latency. The latency was determined as the duration from the beginning of heat stimuli to the occurrence of a hind paw withdrawal reflex, with a cutoff time of 20 seconds to prevent tissue damage.

Immunohistochemistry. The avidin-biotin complex reaction with a fluorescent label was used to visualize the biocytin-marked cells. After completion of the electrophysiological observations, the spinal slice was fixed by immersion in $4 \%$ paraformaldehyde/phosphate buffer overnight. The sections were blocked with $10 \%$ normal goat serum in Tris-Triton (TT) buffer and incubated for 72 hours with rabbit anti-PKC $\gamma$ (1:500 in TT buffer; Santa Cruz Biotechnology Inc.). After wash in TT buffer, sections were incubated for 24 hours with a cocktail of goat anti-rabbit IgG coupled to Alexa Fluor 488 (1:800; Molecular Probes) and Streptavidin Avidin coupled to Texas Red (1:800; Vector Laboratories). The fluorescent images were taken using a confocal microscope (Leica SP2).

Classification criteria of superficial DH neurons. Details of criteria we used to classify superficial DH neurons were published previously $(3,7,8,24)$. Identification of cells in this report is based on the following: TC neurons have somata located in or near the lamina IIo-lamina IIi junction, discharge promptly but briefly to maintained step depolarization, receive monosynaptic DR C-fiber input, and have dendritic arbors distributed principally rostrocaudally for 150 to $275 \mu \mathrm{m}$, with only small dorsoventral and mediolateral extensions. Vertical neurons have soma in lamina II and are distinguished by the following: frequent mEPSCs $(5-7 \mathrm{~Hz})$, a delayed discharge of APs to step depolarization, a monosynaptic DR input from A fibers, and dendrites extensively distributed dorsoventrally $(150-200 \mu \mathrm{m})$ as well as rostrocaudally. Lamina I neurons have a soma that is distinctly larger than adjacent lamina II cells, dendrites distributed extensively rostrocaudally and mediolaterally in the lamina I-II interface partially capping the SDH, and a monosynaptic DR C-fiber input and show a gap or persisting discharge to maintained depolarization. Islet neurons have a relatively large soma, often located near the center of lamina II; have an RMP of usually less than $-50 \mathrm{mV}$; 
give a tonic discharge to maintained depolarization; receive monosynaptic input from DR C fibers; and are characterized by an extended (>400 $\mu \mathrm{m})$, often dense, dendritic arborization oriented rostrocaudally.

Statistics. Results were reported as mean \pm SEM. Statistical analysis of the data was performed using a Student's $t$ test (unpaired) or 1-way ANOVA followed by Bonferroni post-hoc test (GraphPad Prism). Statistical significance was set at $P<0.05$.

Study approval. All the experimental procedures were approved by the Institutional Animal Care and Use Committee of the Fourth Military Medical University in accordance with guidelines set forth by the university for animal research.

\section{Acknowledgments}

We thank Yi Rao (Peking University), Yu-Tian Wang (University of British Columbia, Canada), Xia Zhang (University of Ottawa, Canada), and Christopher G. Myers (University of Michigan) for valuable discussion and constructive comments on the manuscript. Y. Lu, Y. Sun, H. Dong, and L. Xiong were supported by grants from the National Natural Science Foundation of China (81020108020, 31070977, and 30870828 to Y. Lu; 81171051 to Y. Sun; 81128005 and 30972853 to H. Dong; 30930091 to L. Xiong). R.R. Ji was supported by RO1 grants from NIH (DE22743, DE17794, and NS67686).

Received for publication March 21, 2013, and accepted in revised form June 27, 2013.

Address correspondence to: Yan Lu or Lize Xiong, Department of Anesthesiology and Pain Management, Xijing Hospital, Fourth Military Medical University, Xian 710032, China. Phone: 86.29.84771249; Fax: 86.29.84771262; E-mail: yanlu20008@ yahoo.com (Y. Lu), mzkxlz@126.com (L. Xiong).
1. Melzack R, Wall PD. Pain mechanisms: a new theory. Science. 1965;150(3699):971-979.

2. Sandkuhler J. Models and mechanisms of hyperalgesia and allodynia. Physiol Rev. 2009;89(2):707-758

3. Todd AJ. Neuronal circuitry for pain processing in the dorsal horn. Nat Rev Neurosci. 2010;11(12):823-836.

4. Zeilhofer HU, Wildner H, Yevenes GE. Fast synaptic inhibition in spinal sensory processing and pain control. Physiol Rev. 2012;92(1):193-235.

5. Takazawa T, MacDermott AB. Synaptic pathways and inhibitory gates in the spinal cord dorsal horn. Ann N Y Acad Sci. 2010;1198:153-158.

6. Torsney C, MacDermott AB. Disinhibition opens the gate to pathological pain signaling in superficial neurokinin 1 receptor-expressing neurons in rat spinal cord. J Neurosci. 2006;26(6):1833-1843.

7. Lu Y, Perl ER. Modular organization of excitatory circuits between neurons of the spinal superficial dorsal horn (laminae I and II). J Neurosci. 2005; 25(15):3900-3907.

8. Lu Y, Perl ER. A specific inhibitory pathway between substantia gelatinosa neurons receiving direct C-fiber input. J Neurosci. 2003;23(25):8752-8758.

9. Sugiura Y, Lee CL, Perl ER. Central projections of identified, unmyelinated (C) afferent fibers innervating mammalian skin. Science. 1986; 234(4774):358-361.

10. Li L, et al. The functional organization of cutaneous low-threshold mechanosensory neurons. Cell. 2011; 147(7):1615-1627.

11. Basbaum AI, Bautista DM, Scherrer G, Julius D. Cellular and molecular mechanisms of pain. Cell. 2009; 139(2):267-284.

12. Hughes DI, Scott DT, Todd AJ, Riddell JS. Lack of evidence for sprouting of Abeta afferents into the superficial laminas of the spinal cord dorsal horn after nerve section. J Neurosci. 2003;23(29):9491-9499.

13. Yaksh TL. Behavioral and autonomic correlates of the tactile evoked allodynia produced by spinal glycine inhibition: effects of modulatory receptor systems and excitatory amino acid antagonists. Pain. 1989;37(1):111-123.

14. Baba H, et al. Removal of GABAergic inhibition facilitates polysynaptic A fiber-mediated excitatory transmission to the superficial spinal dorsal horn. Mol Cell Neurosci. 2003;24(3):818-830.

15. Schoffnegger D, Ruscheweyh R, Sandkuhler J. Spread of excitation across modality borders in spinal dorsal horn of neuropathic rats. Pain. 2008; 135(3):300-310.

16. Keller AF, Beggs S, Salter MW, De Koninck Y. Transformation of the output of spinal lamina I neurons after nerve injury and microglia stimulation underlying neuropathic pain. Mol Pain. 2007;3:27.

17. Miraucourt LS, Dallel R, Voisin DL. Glycine inhibitory dysfunction turns touch into pain through
PKCgamma interneurons. PLoS One. 2007; 2(11):e1116.

18. Miraucourt LS, Moisset X, Dallel R, Voisin DL. Glycine inhibitory dysfunction induces a selectively dynamic, morphine-resistant, and neurokinin 1 receptor-independent mechanical allodynia. J Neurosci. 2009;29(8):2519-2527.

19. Daniele CA, MacDermott AB. Low-threshold primary afferent drive onto GABAergic interneurons in the superficial dorsal horn of the mouse. J Neurosci. 2009;29(3):686-695.

20. Miraucourt LS, Peirs C, Dallel R, Voisin DL. Glycine inhibitory dysfunction turns touch into pain through astrocyte-derived D-serine. Pain. 2011; 152(6):1340-1348.

21. Malmberg AB, Chen C, Tonegawa S, Basbaum AI. Preserved acute pain and reduced neuropathic pain in mice lacking PKCgamma. Science. 1997; 278(5336):279-283

22. Neumann S, Braz JM, Skinner K, Llewellyn-Smith IJ, Basbaum AI. Innocuous, not noxious, input activates PKCgamma interneurons of the spinal dorsal horn via myelinated afferent fibers. J Neurosci. 2008; 28(32):7936-7944

23. Polgar E, Fowler JH, McGill MM, Todd AJ. The types of neuron which contain protein kinase $\mathrm{C}$ gamma in rat spinal cord. Brain Res. 1999;833(1):71-80.

24. Grudt TJ, Perl ER. Correlations between neuronal morphology and electrophysiological features in the rodent superficial dorsal horn. J Physiol. 2002; 540(pt 1):189-207.

25. Yasaka T, Tiong SY, Hughes DI, Riddell JS, Todd AJ. Populations of inhibitory and excitatory interneurons in lamina II of the adult rat spinal dorsal horn revealed by a combined electrophysiological and anatomical approach. Pain. 2010;151(2):475-488.

26. Zheng J, Lu Y, Perl ER. Inhibitory neurones of the spinal substantia gelatinosa mediate interaction of signals from primary afferents. J Physiol. 2010; 588(pt 12):2065-2075.

27. Lawson SN, Crepps BA, Perl ER. Relationship of substance $P$ to afferent characteristics of dorsal root ganglion neurones in guinea-pig. J Physiol. 1997; 505(pt 1):177-191.

28. Lynn B, Carpenter SE. Primary afferent units from the hairy skin of the rat hind limb. Brain Res. 1982; 238(1):29-43

29. Hughes DI, et al. Morphological, neurochemical and electrophysiological features of parvalbuminexpressing cells: a likely source of axo-axonic inputs in the mouse spinal dorsal horn. J Physiol. 2012; 590(pt 16):3927-3951.

30. Lu Y, Zheng J, Xiong L, Zimmermann M, Yang J. Spinal cord injury-induced attenuation of GABAergic inhibition in spinal dorsal horn circuits is associated with down-regulation of the chloride transporter KCC2 in rat. J Physiol. 2008; 586(pt 23):5701-5715.

31. Lu Y, Perl ER. Selective action of noradrenaline and serotonin on neurones of the spinal superficial dorsal horn in the rat. J Physiol. 2007;582(pt 1):127-136.

32. Ribeiro-da-Silva A, De Koninck Y. Morphological and neurochemical organization of the spinal dorsal horn. In: Basbaum AI, Bushnell MC, eds. Science of Pain. Oxford, United Kingdom: Elsevier; 2009: 279-310.

33. Graham BA, Brichta AM, Callister RJ. Moving from an averaged to specific view of spinal cord pain processing circuits. J Neurophysiol. 2007;98(3):1057-1063.

34. Wang H, Zylka MJ. Mrgprd-expressing polymodal nociceptive neurons innervate most known classes of substantia gelatinosa neurons. J Neurosci. 2009; 29(42):13202-13209.

35. Chen Y, Balasubramanyan S, Lai AY, Todd KG, Smith PA. Effects of sciatic nerve axotomy on excitatory synaptic transmission in rat substantia gelatinosa. J Neurophysiol. 2009;102(6):3203-3215.

36. Gassner M, Leitner J, Gruber-Schoffnegger D, Forsthuber L, Sandkuhler J. Properties of spinal lamina III GABAergic neurons in naive and in neuropathic mice [published online ahead of print March 7, 2013]. Eur J Pain. doi: 10.1002/j.15322149.2013.00294.x.

37. Zylka MJ, Rice FL, Anderson DJ. Topographically distinct epidermal nociceptive circuits revealed by axonal tracers targeted to Mrgprd. Neuron. 2005; 45(1):17-25.

38. Huang W, Simpson RK. Long-term intrathecal administration of glycine prevents mechanical hyperalgesia in a rat model of neuropathic pain. Neurol Res. 2000;22(2):160-164.

39. Khandwala H, Loomis CW. Milacemide, a glycine pro-drug, inhibits strychnine-allodynia without affecting normal nociception in the rat. Pain. 1998; 77(1):87-95.

40. Simpson RK Jr, Gondo M, Robertson CS, Goodman JC. Reduction in the mechanonociceptive response by intrathecal administration of glycine and related compounds. Neurochem Res. 1996; 21(10):1221-1226.

41. Sherman SE, Loomis CW. Morphine insensitive allodynia is produced by intrathecal strychnine in the lightly anesthetized rat. Pain. 1994;56(1):17-29.

42. Onaka M, Minami T, Nishihara I, Ito S. Involvement of glutamate receptors in strychnine- and bicuculline-induced allodynia in conscious mice. Anesthesiology. 1996;84(5):1215-1222.

43. Woolf CJ, Shortland P, Coggeshall RE. Peripheral nerve injury triggers central sprouting of myelinated afferents. Nature. 1992;355(6355):75-78.

44. Shortland P, Woolf CJ. Chronic peripheral nerve section results in a rearrangement of the central 
axonal arborizations of axotomized A beta primary afferent neurons in the rat spinal cord. J Comp Newrol. 1993;330(1):65-82.

45. Koerber HR, Mirnics K, Brown PB, Mendell LM. Central sprouting and functional plasticity of regenerated primary afferents. J Neurosci. 1994; 14(6):3655-3671

46. Koerber HR, Mirnics K, Kavookjian AM, Light AR. Ultrastructural analysis of ectopic synaptic boutons arising from peripherally regenerated primary afferent fibers. J Neurophysiol. 1999;81(4):1636-1644.

47. Nakamura S, Myers RR. Myelinated afferents sprout into lamina II of L3-5 dorsal horn following chronic constriction nerve injury in rats. Brain Res. 1999;818(2):285-290

48. Tong YG, Wang HF, Ju G, Grant G, Hokfelt T, Zhang $X$. Increased uptake and transport of cholera toxin B-subunit in dorsal root ganglion neurons after peripheral axotomy: possible implications for sensory sprouting. J Comp Neurol. 1999; 404(2):143-158.

49. Bao L, et al. Peripheral axotomy induces only very limited sprouting of coarse myelinated afferents into inner lamina II of rat spinal cord. Eur J Neurosci. 2002;16(2):175-185.

50. Takazawa T, MacDermott AB. Glycinergic and GABAergic tonic inhibition fine tune inhibitory control in regionally distinct subpopulations of dorsal horn neurons. J Physiol. 2010;588(pt 14):2571-2587.

51. Coull JA, et al. Trans-synaptic shift in anion gradient in spinal lamina I neurons as a mechanism of neuropathic pain. Nature. 2003;424(6951):938-942.

52. Coull JA, et al. BDNF from microglia causes the shift in neuronal anion gradient underlying neuropathic pain. Nature. 2005;438(7070):1017-1021.

53. Kawasaki Y, Zhang L, Cheng JK, Ji RR. Cytokine mechanisms of central sensitization: distinct and overlapping role of interleukin-1beta, interleukin-6, and tumor necrosis factor-alpha in regulating synaptic and neuronal activity in the superficial spinal cord. J Neurosci. 2008;28(20):5189-5194.

54. Keller AF, Coull JA, Chery N, Poisbeau P, De Koninck Y. Region-specific developmental specialization of GABA-glycine cosynapses in laminas I-II of the rat spinal dorsal horn. J Neurosci. 2001; 21(20):7871-7880.

55. Yasaka T, et al. Cell-type-specific excitatory and inhibitory circuits involving primary afferents in the substantia gelatinosa of the rat spinal dorsal horn in vitro. J Physiol. 2007;581(pt 2):603-618.

56. Harvey RJ, et al. GlyR alpha3: an essential target for spinal PGE2-mediated inflammatory pain sensitization. Science. 2004;304(5672):884-887.
57. Kim YH, et al. TRPV1 in GABAergic interneurons mediates neuropathic mechanical allodynia and disinhibition of the nociceptive circuitry in the spinal cord. Neuron. 2012;74(4):640-647.

58. Melzack R. From the gate to the neuromatrix. Pain. 1999;(suppl 6):S121-S126.

59. Cervero F. The gate theory, then and now. In: Merskey H, Loeser J, Dubner R, eds. The Paths of Pain: 1975-2005. H. Seattle, Washington, USA: IASP Press; 2005:21-41.

60. Bessou P, Perl ER. Response of cutaneous sensory units with unmyelinated fibers to noxious stimuli. J Neurophysiol. 1969;32(6):1025-1043.

61. Perl ER. Ideas about pain, a historical view. Nat Rev Neurosci. 2007;8(1):71-80.

62. Woolf CJ, Ma Q. Nociceptors - noxious stimulus detectors. Neuron. 2007;55(3):353-364

63 . Yoshimura M, Nishi S. Blind patch-clamp recordings from substantia gelatinosa neurons in adult rat spinal cord slices: pharmacological properties of synaptic currents. Neuroscience. 1993;53(2):519-526.

64. Li J, Perl ER. Adenosine inhibition of synaptic transmission in the substantia gelatinosa. J Neurophysiol. 1994;72(4):1611-1621.

65. Kim SH, Chung JM. An experimental model for peripheral neuropathy produced by segmental spinal nerve ligation in the rat. Pain. 1992;50(3):355-363. 